\title{
POWER SECTOR REFORMS AND RESTRUCTURING IN INDIA
}

\author{
S. A. Khaparde \\ Department of Electrical Engineering \\ Indian Institute of Technology - Bombay, Mumbai, India \\ Email: sak@ee.iitb.ac.in
}

\begin{abstract}
KEYWORDS
Electricity Act 2003, Open Access, Market Based Pricing, Transmission Pricing, Central Transmission Utility (CTU)
\end{abstract}

\section{INTRODUCTION}

Power sector across the world is undergoing a lot of restructuring; India is no exception to this. The whole of the power industry in India is undergoing a state of flux. The need for restructuring the power sector was felt due to the scarcity of financial resources available with Central and State Governments, and necessity of improving the technical and commercial efficiency. In some States of India there are multiple private utilities, which are technically and financially in a position to enter the phase of a competitive electricity market. Hence, in 1998 the Regulatory Commissions were formed under the Electricity Regulatory Commissions Act 1998 (Central Law) to promote competition, efficiency and economy in the activities of the electricity industry. Central Electricity Regulatory Commission (CERC) [1] has a key role in rationalizing tariff of generating companies owned or controlled by the Central Government. Ministry of Power [2] has undertaken Accelerated Power Development and Reform Programme (APDRP) from the year 2000-01 with the twin objectives of financial turn-around in the performance of the power sector especially in electric distribution and improvement in quality of supply. Electricity Act 2003 has come into force from June 2003. As the act allows third party sales, it introduces the concept of trading bulk electricity. The act also provides open access to transmission as well as distribution of electricity. Some of the important issues addressed by this Act and their impact on power system restructuring are discussed in this paper.

\section{PROPOSED MODEL FOR RESTRUCTURING IN INDIA [3]}

In many parts of the world wherever unbundling, i.e. separation of generation, transmission and distribution has taken place, the two models are more prevalent for system operation. The first one is Independent System Operator (ISO) model and the other is Transmission System Operator (TSO) model. In ISO model, transmission companies are also permitted to own, manage and control generation and distribution companies, an independent system operator is created to facilitate open access and competitive markets.

In TSO model, operation of the grid and ownership of the grid are integrated in a single entity, which is responsible for development of transmission system and to provide non-discriminatory open access to all eligible market participants. Neutrality is an important aspect of the TSO to ensure an efficient market. In view of this, TSO model seems to be most suitable for future restructured electricity market in India. This is 
because the government owned transmission company is merely responsible to provide non-discriminatory open access. Some of the developed countries are also moving away from ISO model by formation of Regional Transmission Organizations (RTO), which will finally converge as a TSO model.

Even though the conditions in Indian power market are not yet ripe for introducing retail competition, the necessities in a deregulated power market can be summarized below:

- Non-discriminatory open access to transmission network is a pre-requisite for ensuring competition in wholesale power trading.

- The system operation functions at the national level can be handled by central transmission utility while state transmission utilities can manage State Load Despatch Centres (SLDCs) similar to TSO concept.

- The regional electricity boards will have the responsibility of managing the power exchanges while the Regional Load Despatch Centres (RLDCs) will manage the overall integrated operation of power system like outage planning, relay co-ordination, islanding schemes, etc.

Some of the main characteristics of TSO model are also incorporated in the Electricity Act 2003.

\section{ELECTRICITY ACT 2003}

The Electricity Bill 2003, approved in Indian Parliament in May 2003, aims to enhance the scope of power sector reforms. This act consolidates all the existing laws and introduces provisions with respect to new developments in the sector. It focuses on creating competition, protecting consumer interests, rationalizing tariff, etc.

All the necessary powers including issue of licenses are given to the regulators which are made independent entities from the government.

\subsection{Salient Features [4]}

Some of the major provisions of the Electricity Act are:

1. Generation has been delicensed and captive generation is being freely encouraged and permitted. For hydro projects, an approval of the State Government and clearance from the Central Electricity Authority (CEA) [5] are needed to check the safety aspects and optimum utilization of water resources.

2. There will be Government owned Transmission Utility at the Central as well as State level, having the responsibility of ensuring that the transmission network is developed in a planned and co-ordinated manner to meet the requirements of the sector. The load dispatch function can be integrated with or separated from the Transmission Utility and in either case it will remain under Government control.

3. Provision for private transmission licensees has been made in this act.

4. Open access in transmission with provision of surcharge for cross subsidy and this surcharge will be gradually phased out.

5. Distribution licensees are free to undertake generation and generating companies are free to take up distribution licensees.

6. For rural and remote areas stand alone systems for generation and distribution would be permitted. This provision seems to be aimed at encouraging Captive Power Plants (CPPs) and Distributed Generation (DG). 
7. For rural areas decentralized management of distribution through Panchayats, Cooperatives, etc. would be permitted.

8. Regulatory Commissions are authorized to issue a license for power trading and they will fix up the upper limit on power trading margins.

9. If there is directly commercial agreement between a consumer and a generating company or trader, the price of power would not be regulated and only the transmission and wheeling charges with surcharge would be regulated.

10. State Governments can convert State Electricity Boards (SEBs) into companies or continue them as distribution licensees.

11. An Appellate Tribunal has been created for disposal of appeals against the decision of the CERC and State Electricity Regulatory Commissions (SERC) so that there is speedy disposal of such matters. The SERC is a mandatory requirement.

In the following sections the impact of this act on generation, transmission and distribution is analyzed.

\subsection{Generation of Electricity}

Any generating company may establish, operate and maintain a generating station without obtaining a license if it complies with the technical standards related to the connectivity of grid as specified by CEA. The generating company should establish, operate and maintain generating stations, tie-lines, substations and dedicated transmission lines.

According to the $16^{\text {th }}$ Electric Power survey conducted by CEA, the country has energy shortage of $7.8 \%$ and peaking shortage of $13 \%$. The capacity addition required by the end of $11^{\text {th }}$ plan (by year 2012) to meet these shortages is nearly $100 \mathrm{GW}$. Therefore, in July 2001 Ministry of Power suggested to liberalize the framework for setting up of CPPs and utilize their surplus output for the benefit of consumers.

As per the reports published by Oxford Institute for Energy Studies (OIES) [6] the Indian Government should do more to encourage and facilitate local private investment in small-scale distributed electricity generation capacity, as part of a 'bottom-up' solution to electricity sector reform, rather than continuing its attempts to force through 'top-down' reform on entrenched local interest groups - especially SEBs.

Previously as per Electricity (Supply) Act 1948 all these plants required clearance certificate from the utility. After the enactment of Electricity Act 2003 any one can construct, maintain and operate the CPP and dedicated transmission lines, provided that the supply of electricity from the plant shall be regulated in the same manner as that of a generating station. Every CPP owner has a right to open access for transmission of electricity provided that there is an availability of adequate transmission facility, which should be determined by central/state transmission utility. Any dispute regarding availability of transmission lines shall be resolved upon by the Regulatory Commission.

\subsection{Transmission of Electricity}

In case of Inter-State transmission, the Act proposes region-wise demarcation of the country and the central government should establish National Load Despatch Centre (NLDC) for optimum scheduling and dispatch of electricity amongst the RLDCs. The 
NLDC and RLDC will not be involved in the business of power trading. The RLDC will work as per the Indian Electricity Grid Code (IEGC) to ensure integrated operation of the power system in the concerned regions. It has to monitor grid operations, keep accounts of the quantity of electricity transmitted through the regional grids, exercise supervision and control over the Intra-State transmission and it will be responsible for carrying out real time operations for grid control and dispatch of electricity within the state through secure and economic operation of the state grid in accordance with grid standards and the state grid code.

The possible tariff for transmission services can be divided into three parts. The proposed components reflecting the cost of various activities will be:

Use of network charges - This will reflect costs of capital investments and the maintenance and operation of a transmission system to transfer bulk power to and from different locations. The use of network charges would be worked out on distance slabs to reflect the distance traveled by the energy transmitted.

System operation charges - This is meant for accommodating the costs associated with operating the LDC. The costs of owning and maintaining the LDC should be included. The system operation charges shall be charged to the users based on total transacted energy.

Reactive power charges - This is a variable charge depending upon the voltage related drawl of reactive power. Reactive power drawl by beneficiaries is to be priced as per the voltage level of the system i.e. beneficiary pays for reactive power drawl when voltage at the metering point is below $97 \%$ and beneficiary gets paid when the voltage is above 103 $\%$.

\subsection{Distribution of Electricity}

It shall be the duty of a distribution licensee to develop and maintain an efficient, coordinated and economical distribution system in its area of supply and to supply electricity in accordance with the provisions contained in this act. There may not be any exclusive monopolies in distribution circles. The act allows non-exclusive licensing and parallel distribution networks, thus restricting the scope of monopolies in the distribution circles.

Where the State Commission permits a consumer or class of consumers to receive supply of electricity from a person other than the distribution licensee of his area of supply, such consumer shall be liable to pay an additional surcharge on the charges of wheeling, as may be specified by the State Commission, to meet the fixed cost of such distribution licensee arising out of his obligation to supply.

Distribution companies have been given mandate for achieving complete metering within two years from the enactment of the law.

Recently CERC has published the Order regarding open access in Inter-State transmission. The next section outlines the salient features of this Order.

\section{OPEN ACCESS}

Before the enactment of the Electricity Act 2003 (hereinafter referred to as 'the Act'), the legal framework did not offer any choice to the distribution companies and the consumers in the selection of suppliers of electricity. The Act has enabled the distribution companies and the consumers to have choice in the matter of supplies of electricity. Similarly, the 
generator also has choice to select among the distribution companies. The Act specifies the provisions for non-discriminatory use of transmission lines or distribution system or associated facilities with such lines or system by any licensee or consumer or a person engaged in generation. This is termed as 'open access'. In order to give sound shape to the new philosophy of non-discriminatory open access in transmission, a concept paper was prepared and published by CERC on $14^{\text {th }}$ August 2003, which was circulated among different stakeholders and interested persons with a view to eliciting their suggestions before formulating the regulations envisaged in the Act. Open hearing on the issues raised in the concept paper was held on $24^{\text {th }}$ and $25^{\text {th }}$ September 2003 . About 45 entities including State Electricity Regulatory Commissions, State Governments, Central Transmission Utilities, Non-Government Organizations, industries and individuals participated in the hearing. The discussions were aimed at deciding policy over the following issues:

- Provisions for non-discriminatory use of inter-state transmission system.

- The payment of transmission charges and surcharge thereon for use of the transmission system belonging to the Central Transmission Utility and other interstate transmission licensees.

- Reducing and eliminating the surcharge as the cross subsidies in a phased manner.

- Specification of rates, charges and terms and conditions for use of inter-state transmission facilities, if these can not be mutually agreed between the licensees.

In the concept paper, different methods of pricing such as contract path method, postage stamp method, MW-mile method and congestion pricing method have been discussed. A new concept of incremental postage stamp method in addition to the traditional contract path method was also discussed.

Contract path method is presently applied for determination of wheeling charges for State Electricity Board (SEB) system used for inter-state transmission. National Thermal Power Corporation (NTPC), Western Regional Electricity Board (WREB) supported this method; the arguments in favor being simplicity, acceptability and distance sensitivity. CEA and Eastern Regional Electricity Board (EREB) opposed this method; arguments against being that the actual path may be different from contract path and that it would not reflect true cost in many cases such as transmission taking place in displacement mode.

Incremental Postage Stamp method envisages the country to be demarcated into squares of $100 \mathrm{~km} \times 100 \mathrm{~km}$ and the charges payable by the open access customer are determined by counting the squares vertically and horizontally from the source to sink of the transaction. The method makes the rate sensitive to distances exceeding $100 \mathrm{~km}$. Grid Corporation of Orissa Ltd. (GRIDCO), West Bengal State Electricity Board (WBSEB), Railways opined in favor of this method. Madhya Pradesh Electricity Regulatory Commission (MPERC) recommended application of this method in cases where the line involved in power flow can not be determined. The Energy and Resources Institute (TERI) argued against adoption of this method expressing a view that counting rule for the stamps would lead to pancaking; sharing of stamps between State Transmission Utility (STU) and Central Transmission Utility (CTU) would add complexity.

In Flow Based Pricing or Megawatt-mile method, the transmission rates explicitly reflect the cost of transmission, based on both the power flow and the network usage between the receipt and delivery points. MW-mile is a sophisticated analytical method 
that involves load flow analysis to model power flows on the transmission network to determine charges and hence requires complex data. Southern Regional Electricity Board (SERB) and Industrial Development Bank of India (IDBI) pointed out that MW-mile method is most scientific but too complex to be applied in present conditions.

The annual transmission service charges of CTU, under Availability Based Tariff (ABT) regime are apportioned to different beneficiaries pro-rata on the basis of their capacity allocation out of the total capacity handled by the transmission system in the region. This takes into account the allocated central generating capacity to different states, bilateral exchanges as well as capacity brought in through trading. In the pre-ABT period, the transmission service charges apportioning was done pro-rata on energy drawal basis. In a sense, for a region, the transmission service charges of CTU are recovered from the state beneficiaries on 'Regional Postage Stamp' basis. In case of inter-regional transactions, the drawing utility has to pay to CTU, transmission charges applicable to its region and wheeling charges for the exporting region. At present, there are no wheeling charges for the use of CTU network in the intermediary region. Bihar State Electricity Board (BSEB) has strongly opposed the present practice of not levying the wheeling charges for intermediary regions.

CEA has come out with an improvised version of incremental postage stamp method, in which the country is demarcated into 14 zones, each represented by one or more states. Stamps between various zones are counted not only by the physical distance but also by taking into consideration the mode of transmission (i.e. actual flow or displacement). CEA has also suggested a matrix of stamps between various zones which are further based on notional distances. The notional distance captures the existing flow pattern and impact of incremental flow due to open access transaction. Thus, this method tries to replicate results obtained from MW-mile method, without going into complexities of the later.

Some different thoughts like 'Single National Postage Stamp' Methods and 'Free Wheeling' were also proposed by some of the participants. The former was ruled out because of the regional basis of the electricity grid and lack of capacity and capability to transfer freely substantive amount of power across the region. The later was opposed by the state beneficiaries.

There was no consensus among the stakeholders and others on adoption of any particular method for pricing. Many of the participants were in favor of continuation of the existing regional postage stamp method whereas some others favored either incremental postage stamp method or CEA's improvised zonal postage stamp method.

After taking cognizance of the views expressed by various stakeholders, the Commission has ordered that the existing Regional Postage Stamp method of transmission pricing as per the Commission Notification dated 26.3.2001 shall be followed in respect of all such entities who are now eligible to seek open access for interState Transmission. The Commission has opted in favor of the existing method so as to set in motion with immediate effect, the process of open access in inter-State Transmission. The Commission has also ordered that the open access customers shall also have option like existing beneficiaries to enter into long term bulk power transmission agreement for use of inter-State transmission system and in such a case the transmission service charge will be determined according to the tariff norms as notified 
by the Commission. This will maintain continuity and allow time to gather practical experience in the matter.

The issues other than transmission pricing, like customer categorization were also mentioned in the concept paper. The Commission has categorized the open access customers into two broad categories: (i) Short Term Customers, who intend to avail of transmission service up to one year and (ii) Long Term Customers, who intend to avail of the transmission access for 5 years or more. Allotment priority of long term open access customers shall be higher than the short term customers.

The Commission has also ordered that the nodal agency for long term access shall be the Central Transmission Utility (CTU), which is POWERGRID at present. The nodal agency for short term access shall be the RLDC of the region in which the point of drawal is located.

The commission order envisaged payment of scheduling and system operation charges to RLDCs and SLDCs. The RLDC charges per MW per year may be calculated by dividing RLDC charges approved by the commission for the year 2003-04 by the installed capacity of the central sector stations in the country. The scheduling and system operation charges shall be recovered from generators also, if they have sought open access.

The Commission has also ordered that any open access customer directly connected to the CTU transmission network shall be treated in the identical manner as the existing entities and he will be liable to pay unscheduled energy interchange (UI) charges as per the ABT tariff to the RLDC pool for any deviations in energy schedule from the day ahead schedule given by him. As regards open access customers embedded in the state transmission network, the Commission has ordered that the concerned SLDC shall forward its own schedule and the schedule of embedded customers separately to the RLDC on day ahead basis. For any deviations from the schedules, RLDC will present a composite UI bill to the State as is being done now.

The Availability Based Tariff (ABT) has been implemented by Central Commission in all the five regions of the country which has built-in mechanism for energy accounting in respect of any deviations from the declared schedules. The Commission has recommended that same methodology and procedure for energy accounting should also be implemented at the State level also.

Regarding an important issue of handling of losses, the Commission sticks to the existing methodology in which the actual losses in the CTU network of a region are calculated from the Special Energy Meter (SEM) readings at the point of generation and drawal. The weekly average losses in percentage are then found in this manner for a region. These percentage average losses of the previous week are then applied to arrive at drawal schedule of each beneficiary in the region. The slight mismatch in the estimated losses considered in the scheduling process and actual losses during the week get adjusted in the settlement of (UI) accounts by RLDC.

It will be mandatory for all open access inter-State Transmission customers to

provide special energy meters with requisite communication facility as per the requirement of RLDC/CTU.

\section{REFERENCES}

[1] Central Electricity Regulatory Commission Website (http://www.cercind.org). 
[2] Ministry of Power, Government of India Website (http://powermin.nic.in).

[3] Vindal, S. S., Saxena, N. S., and Srivastava, S. C. Industry Structure Under Deregulated Wholesale Power Markets in India, Proceedings of International Conference on Present and Future Trends in Transmission and Convergence, New Delhi, India, December 2002.

[4] Published in Gazette of India The Electricity Act, 2003. India: Universal Law Publication Company Pvt. Ltd.

[5] Central Electricity Authority of India Website (http://www.cea.nic.in).

[6] Oxford Institute for Energy Studies Website (http://www.oxfordenergy.org). 